\title{
CONHECIMENTO E USO DE TRATAMENTOS ALTERNATIVOS PARA ICTERÍCIA NEONATAL
}

\author{
Bruna Moretti Luchesi ${ }^{1}$, Maria Isabel Ruiz Beretta ${ }^{2}$, Giselle Dupas ${ }^{3}$
}

\begin{abstract}
RESUMO: A icterícia é um agravo frequente no período neonatal sendo a fototerapia o recurso mais utilizado para o seu tratamento, embora existam tratamentos alternativos. Objetivando identificar o conhecimento materno sobre tratamentos alternativos e seu uso pelas mães, foi desenvolvida uma pesquisa qualitativa em uma maternidade do interior paulista. Participaram 26 mães de neonatos em tratamento fototerápico; os dados foram coletados por meio de entrevistas gravadas e posteriormente transcritas. A maioria conhecia algum tratamento alternativo; referiram banhos com picão, telha virgem, rosa-branca e exposição ao sol; e algumas relataram uso prévio ou pretensão em usá-los, bem como sua percepção sobre a eficácia, ou não, dos tratamentos alternativos. Os resultados mostram a importância da interação entre o conhecimento das mães e o dos profissionais de saúde, com vistas à melhoria do cuidado no período pós-alta hospitalar, em continuidade ao tratamento, e indicação em casos de icterícia neonatal de manifestação tardia. PALAVRAS-CHAVE: Icterícia neonatal; Terapias alternativas; Mães.
\end{abstract}

\section{KNOWLEDGE AND USE OF ALTERNATIVE TREATMENTS FOR NEONATAL JAUNDICE}

\begin{abstract}
Jaundice is a common harm in the neonatal period, and the phototherapy is the most used resource for treatment, although there are alternative treatments. To identify the maternal knowledge about alternative treatments and their use by mothers, we developed a qualitative research in a hospital in São Paulo. The participants included 26 mothers of newborns under phototherapy, the data was collected through interviews recorded and transcribed. Most knew some alternative treatment; reporting bathing prick, tile virgin, white-rose and sun exposure. Some of them reported previous use or intend to use them, as well as their perception on the effectiveness, or not, of alternative treatments. The results show the importance of interaction between the knowledge of mothers and health professionals, in order to improve care in the post-discharge period, the continuing treatment, and its prescription in cases of late onset of neonatal jaundice. KEYWORDS: Neonatal jaundice; Alternative Therapies; Mothers.

\section{CONOCIMIENTO Y USO DE TRATAMIENTOS ALTERNATIVOS PARA ICTERICIA NEONATAL}

\begin{abstract}
RESUMEN: La ictericia es un agravio frecuente en periodo neonatal siendo la fototerapia el recurso más utilizado para su tratamiento, aunque existan tratamientos alternativos. Con el objetivo de identificar el conocimiento materno acerca de tratamientos alternativos y su uso por las madres, fue desarrollada una investigación cualitativa en una maternidad del interior de São Paulo. Han participado 26 madres de neonatos en tratamiento fototerápico; los datos fueron recogidos por medio de entrevistas grabadas y posteriormente transcriptas. La mayoría conocía algún tratamiento alternativo; hablaron de baños con picão (Bidens graveolens), teja virgen, rosa-branca (Hibiscus mutabilis) y exposición al sol; y algunas relataron uso previo o pretensión en usarlos, así como su percepción sobre la eficacia, o no, de los tratamientos alternativos. Los resultados muestran la importancia de la interación entre el conocimiento de las madres y el de los profesionales de salud, para la mejoría del cuidado en periodo pos alta hospitalar, en continuidad al tratamiento, e indicación en casos de ictericia neonatal de manifestación tardía.
\end{abstract}

PALABRAS CLAVE: Ictericia neonatal; Terapias alternativas; Madres.

\footnotetext{
'Enfermeira. Mestranda do Programa de Pós-Graduação em Enfermagem da Universidade Federal de São Carlos-UFSCar. Bolsista FAPESP. ${ }^{2}$ Enfermeira. Doutora em Educação. Professora Associada da UFSCar.

${ }^{3}$ Enfermeira. Doutora em Enfermagem. Professora Associada da UFSCar.
}

\author{
Autor correspondente: \\ Giselle Dupas \\ Universidade Federal de São Carlos \\ Av Dr Renato de Toledo Porto, 460 - 13564190 - São Carlos-SP, Brasil \\ E-mail: gdupas@ufscar.br
}

Recebido: 14/10/09

Aprovado: 04/02/10

Cogitare Enferm. 2010 Jul/Set; 15(3):506-12 


\section{INTRODUÇÃO}

A hiperbilirrubinemia é definida como uma alta concentração de bilirrubina no plasma, sendo apresentada pela maioria dos recém nascidos $(\mathrm{RN})$ nos primeiros dias de vida; leva à icterícia, que é a coloração amarelada da pele, escleróticas e mucosas, pelo depósito de bilirrubina nestes locais ${ }^{(1)}$.

A icterícia, na maioria dos casos em que ocorre, é caracterizada como fisiológica, se iniciando após as primeiras 24 horas de vida do $\mathrm{RN}$ e durando, em média, uma semana ${ }^{(2-3)}$. Mas, também pode se relacionar a uma síndrome ou doença, surgindo antes das primeiras 24 horas de vida ${ }^{(3)}$. Diante disto, é importante que o tratamento da mesma seja realizado imediatamente após sua descoberta.

A fototerapia é o tratamento mais utilizado no mundo para tratar a icterícia neonatal, por ser altamente eficaz e não ter efeitos colaterais que justifiquem sua contraindicação ${ }^{(2)}$.

Porém, quando os RN permanecem no hospital por pouco tempo, a observação da icterícia fisiológica é dificultada, já que a mesma aparece após as primeiras 24 horas de vida, não permitindo intervenções e necessitando, muitas vezes, de readmissão do $\mathrm{RN}$ para o tratamento fototerápico, o que pode gerar mais gastos e, além disso, prejudicar o aleitamento materno ${ }^{(4)}$. Devido a isto e outros fatores associados, o Departamento de Neonatologia da Sociedade Brasileira de Pediatria recomenda que a alta hospitalar de RNs a termo, saudáveis e sem intercorrências, seja após 48 horas de vida e ainda que haja um retorno ambulatorial de 48 e ainda a 72 horas após a alta ${ }^{(5)}$.

Muitas vezes, a alta dos RN é concedida antes deste período, ou antes que se possa descobrir a doença. O retorno do paciente ao hospital torna-se, então, necessário para que seja realizado o tratamento fototerápico. As mães, por estarem em casa, podem não querer retornar ao hospital e, por isso, podem tentar alternativas na própria casa para cuidar do neonato.

A mulher, principalmente a mãe, exerce o papel de personagem principal no cuidado e é a mesma quem encaminha os cuidados para os problemas de saúde dos seus familiares. Para enfrentar as situações de doença, ela tende a buscar apoio não só dos serviços de saúde ou da medicina oficial, mas também nos denominados "agentes extra-oficiais", a chamada medicina popular. Os conhecimentos da medicina popular são passados de geração em geração, principalmente entre o sexo feminino ${ }^{(6)}$. Medicina popular seriam os "conhecimentos e práticas arraigados tanto à cultura indígena quanto aos valores trazidos por colonizadores", sendo que foram incorporados e respeitados no cotidiano da população ${ }^{(7: 38)}$.

O que explica a origem das crenças e práticas populares é a experiência individual na sociedade e na cultura. Os resultados podem provocar repercussões sociais importantes, fazendo com que as pessoas acreditem nestas práticas ${ }^{(8)}$.

O uso das medicinas alternativas e complementares está crescendo em adultos e crianças ${ }^{(9)}$. Muitas pessoas as utilizam de forma concomitante ou alternada à medicina tradicional, como dito anteriormente. Quanto ao uso caseiro de plantas medicinais, podemos destacar sua influência no tratamento de problemas de saúde das crianças. Apesar de não serem recomendadas, algumas práticas ainda continuam a fazer parte do dia-a-dia de mães no cuidado de suas crianças porque estão baseadas na vivência, experimentação e avaliação do sucesso de seu uso diante de problemas de saúde ${ }^{(8)}$.

Num estudo que objetivou identificar os principais recursos populares que mães/pais ou responsáveis utilizam nos cuidados em saúde de seus respectivos filhos ou tutelados, bem como investigar a credibilidade depositada nestes recursos diante dos oferecidos pelo sistema biomédico, todas as pessoas entrevistadas disseram utilizar algum tipo de recurso popular. Dentre os motivos que envolvem o uso destes recursos estão desde as questões financeiras e a facilidade de acesso até o fato de ser um costume da família ou do círculo de amigos e $\operatorname{conhecidos}^{(8)}$. Tais motivos também foram citados em outro estudo, que acrescentou, além disto, o fato das pessoas acreditarem que as plantas medicinais são inofensivas e mostrarem insatisfação com a medicina tradicional ${ }^{(10)}$.

Sabe-se que a medicina popular possui vários tratamentos para a icterícia, e que os mesmos são amplamente utilizados pelas mães dos $\mathrm{RN}$ e pelas suas respectivas famílias. É essencial que os profissionais de saúde conheçam as crendices e práticas populares relacionadas ao processo saúde-doença da população e se familiarizem com as mesmas, aprendendo a lidar com os valores, crenças e hábitos dos mesmos. Existem muitas situações vivenciadas pelos profissionais de saúde em que a cultura popular é usada na reabilitação e cura da saúde ${ }^{(11)}$.

Com base no exposto, este estudo teve como objetivo identificar o conhecimento materno sobre tratamentos alternativos para cuidar da icterícia neonatal, 
bem como saber se esses tratamentos alternativos já foram utilizados.

\section{MÉTODOS}

Estudo transversal, descritivo, baseado nos pressupostos da pesquisa qualitativa. O trabalho foi realizado numa maternidade localizada em um município na região central do Estado de São Paulo.

A amostra foi selecionada por conveniência e correspondeu a 26 mães. Os critérios de inclusão foram ser mãe de um RN nascido na maternidade, com diagnóstico de icterícia no prontuário, em tratamento fototerápico e internado na maternidade referida. Foram escolhidas mães de RN em tratamento fototerápico na maternidade pela dificuldade em encontrar mães que tinham $\mathrm{RN}$ com icterícia e que conheciam ou estavam fazendo uso de tratamentos alternativos em casa.

Todos os cuidados éticos que regem pesquisas com seres humanos foram observados, segundo a Resolução n. 196/96. O projeto foi aprovado pelo Comitê de Ética em Pesquisa da Universidade (CAAE n. 3213.0.000.135-07 Parecer 357/2007) e a coleta de dados teve início após a leitura e assinatura do Termo de Consentimento Livre e Esclarecido. Para garantir o anonimato dos sujeitos, os nomes dos participantes foram substituídos por números.

Foram realizadas visitas diárias à maternidade no período de coleta de dados (fevereiro de 2008 a abril de 2008) e todas as mães que respeitavam os critérios de inclusão participaram do estudo. Foram feitas entrevistas, na própria maternidade, que seguiram um roteiro previamente elaborado, contendo questões fechadas para caracterização das mães quanto às condições sociodemográficas e o seguinte questionamento: "Sabe de algum tratamento caseiro para cuidar da icterícia? Já usou? Funcionou?"

Os dados de caracterização foram organizados e analisados estatisticamente. As entrevistas foram gravadas e posteriormente transcritas. Foi realizada uma análise de conteúdo dos dados obtidos, em especial a análise temática, procurando as regularidades nos discursos, identificando os núcleos do estudo, categorizando-os e, finalmente, feita sua análise ${ }^{(12)}$.

\section{RESULTADOS}

A idade média das mães foi de 24,6 anos, entre um máximo de 38 anos e um mínimo de 16 anos. Em relação ao estado civil, a grande maioria das mães era casada (69\%), outra parcela era solteira (27\%) e $4 \%$ eram divorciadas. Das 26 mães entrevistadas, 11 $(42,3 \%)$ já possuiam um ou mais filhos antes do RN atual e 15 eram mães de primeiro filho. Das 11 que já possuiam filhos, 36,3\% tiveram experiência anterior de icterícia com o(s) filho(s). A escolaridade das mães variou, porém a maioria delas (50\%) tinha completado o segundo grau. A profissão das mães também foi bem diversificada, mas a maioria delas $(34,6 \%)$ era "do lar", e trabalhando na própria casa.

As mães entrevistadas foram questionadas se conheciam algum tratamento alternativo/caseiro para cuidar da icterícia. Obtivemos resposta de seis mães $(23 \%)$ que nunca ouviram falar de algum outro tratamento. As outras 20 (77\%) conheciam, sendo possível identificar os seguintes:

- Banho de "picão"

- Banho de telha virgem

- Banho de rosa-branca

- Banho de sol

Na categoria Banho de "picão" pudemos identificar 12 mães que conhecem ou já ouviram falar desta forma de tratamento caseiro para a icterícia. Dentro desta categoria, encontramos subcategorias que compreendem as mães que disseram ter ouvido falar que é bom, as mães que já usaram e funcionou, e uma mãe que já usou e não viu resultado.

Entre as mães que ouviram falar que é bom e funciona, podemos citar os seguintes depoimentos:

O que toda avó fala, banho de picão, não usei, mas queriam dar nela e eu falei 'não, ela vai para o médico' [...]. A minha avó jura de pé junto que é tiro e queda. (Mãe 1)

Eu ouvi [sobre] um banho, mas é que eu não sei, é de uma erva, mas eu não sei o nome. Acho que é picão, mas sei que este banho resolve, já me falaram. Não sei quem que foi, acho que foi minha vizinha, que ela $f e z$, e acho que deu resultado, mas não tentei, porque não saí daqui. (Mãe 16)

Entre as que já usaram e funcionou temos:

[...] eu usei o banho de picão. É só colocar ele [o picão] na água e dar banho assim [...]. Eu acho que melhorou, ele tava mais feio, viu. O xixi melhorou. Antes tava aquele xixi pastoso, e agora não tá mais, melhorou 
um pouco mas não totalmente. Não foi eficaz, mas ajudou muito. (Mãe 4)

É o picão, que eu já usei com a minha outra filha e funcionou [...]. Mas o picão foi a minha vó que pegou pra eu conhecer. Aí, dá o banho três dias, que eles falam que tem que ser três dias. Porque eu não sabia que existia este tratamento aqui da luz. (Mãe 12)

E a mãe que referiu já ter usado o tratamento e não viu resultado, assim se pronunciou:

[...] banho de picão, se eu não me engano, também dei, mas eu não vi resultado. (Mãe 17)

O picão é uma herbácea que chega até 60 centímetros de altura e possui flores amarelas; seu nome botânico é Bidens pilosa. Ele é muito usado na forma de chá para combater icterícia e hepatite. Pode ser usado em duas formas: no uso interno, em que o chá é ingerido, e no uso externo, em que o chá é usado para banho. Para se fazer o chá é aproveitada toda a planta. Até o momento, não foi encontrada ação tóxica pela planta, porém, assim como qualquer planta, ela não deve ser consumida em excesso ${ }^{(13)}$.

$\mathrm{Na}$ categoria Banho de telha virgem, pudemos identificar seis mães que conhecem ou já ouviram falar desta forma de tratamento caseiro. Dentro desta categoria, encontramos uma subcategoria que se refere às mães que disseram ter ouvido falar. Dessas, podemos citar os seguintes exemplos:

[...] já ouvi falar da telha, que você esquenta a telha e põe na água, mas não sei se funciona. Já ouvi falar. (Mãe 12)

Aqui eu ouvi falar de banho de telha, mas não sei, nunca dei. (Mãe 25)

Tivemos duas mães que já ouviram falar dos banhos de picão e de telha virgem, e que disseram pretender usar quando saírem da maternidade assim comentaram:

Sei, falaram que é bom telha e picão, mas eu não usei porque não saí daqui né, não fui embora ainda [...]. Mas pretendo usar, porque eu já vi muitas crianças e funcionou. Porque eu já tive, e minha mãe curou eu com isso, então funciona. E tem que funcionar, porque eu não quero voltar aqui mais não [...]. Vou usar a telha. Qualquer um, tudo que falarem que é bom eu vou usar. (Mãe 5)

Já ouvi [falar de] banho de telha e chá de picão, mas vou dar na hora chegar em casa. Acho que resolve, os antigos comentam que funciona. (Mãe 26)

Sobre o Banho de rosa-branca, tivemos apenas uma mãe que o citou:

Ferve e joga a rosa-branca, as pétalas na água e você dá o banho [...]. Mas eu não fiz nada [...]. Minha sogra já usou nos dois filhos dela. Todas a pessoas que conversei, a maioria usaram também, não fizeram fototerapia. Mas eu preferi não arriscar, é melhor né? (Mãe 2)

E também tivemos a categoria Banho de sol, em que 11 mães o citaram até como uma indicação médica e de enfermagem. Pudemos observar as seguintes subcategorias: falaram que é bom, pretendem usar, e já usou e não resolveu. Das que falaram que é bom, podemos citar:

Não, só banho de sol. Falaram pra mim dar. Aí, só ontem de manhã que eu aproveitei e hoje de manhã, antes dela vir pra cá. (Mãe 11)

O que eu ouvi falar é que é bom tomar o sol da manhã, durante quinze minutos, e da tarde. Mas tem que tampar o rostinho dele, para não ir sol. (Mãe 21)

Eles falaram aqui mesmo que se fosse mais fraco era para fazer em casa. Deixar um pouquinho no sol de manhã e à tarde, mas como eu não fui embora eu não fiz. (Mãe 23)

Somente uma mãe ainda pretende usar:

Só o sol mesmo, o banho de sol. Enão usei porque não saí daqui, mas quando eu sair eu vou usar. (Mãe 9)

E duas mães usaram e não resolveu:

Eu já ouvi falar que o médico pediu para eu dar banho de sol, que eu dei mas não resolveu muito [...]. (Mãe 17)

Não, só o banho de sol que eles falam. Dei uns três dias mas não adiantou. (Mãe 18) 
Segundo a Secretaria Municipal de Saúde de Campinas, o banho de sol é muito importante para o $\mathrm{RN}$, pois além de ajudar no desenvolvimento ósseo, auxilia na redução da icterícia. O mesmo deve ser realizado com a criança vestindo o mínimo de roupas possível, durante cinco minutos, tempo que deve ser aumentado gradativamente até cerca de 15 minutos por dia. Deve ocorrer antes das 10 da manhã e após as 16 horas. É importante ressaltar que o banho pode ajudar na redução da icterícia, mas não atua como tratamento. Caso a mãe perceba uma coloração muito amarelada da pele, deve levar o RN para avaliação ${ }^{(14)}$.

É importante salientar, também, que nas falas das mães aparece muito a questão cultural, em que as tradições da medicina popular são passadas de geração em geração. Ainda, vimos que muitas mães ouviram falar do tratamento pela avó, pela mãe ou até por uma vizinha. A cultura é "um padrão de dogmas, crenças e práticas que, de maneira inconsciente, fundamenta ou orienta os objetivos e decisões de um grupo de pessoas"(11:13). A cultura, ainda segundo os mesmo autores, é fundamental para incorporar as experiências anteriores, influenciar ações e pensamentos do presente e passar as tradições para os futuros membros do grupo, como se constatou nesta pesquisa. Os mesmos autores ressaltam que, geralmente, são as pessoas mais velhas da família que influenciam culturalmente e, devido à pouca experiência das mães, muitas crenças populares fazem parte do cuidado prestado às crianças.

Além disso, como muitas destas práticas e crenças populares existem há muito tempo e continuam sendo utilizadas até os dias de hoje pelas famílias, elas não devem ser banalizadas, e devendo se considerar a importância destas nos cuidados curativos e preventivos de saúde. É muito apropriado que a Enfermagem amplie seus conhecimentos sobre as práticas populares para que possa garantir uma assistência de qualidade às crianças e suas mães ${ }^{(11)}$.

Em um estudo realizado no Município de São Paulo com 120 mães de crianças com até cinco anos de idade, e que objetivou verificar a utilização da fototerapia nas crianças, foi constatado que $66 \%$ das mães utilizavam algum tipo de planta medicinal para o tratamento de doenças em seus filhos. Foram citados mais de 20 nomes de plantas, das quais a camomila e a erva-doce foram as mais mencionadas. O estudo conclui que é importante que os profissionais de saúde, especialmente os enfermeiros, conheçam a fitoterapia como prática complementar, podendo ser pessoas importantes para preservação da sabedoria popular ${ }^{(15)}$.

Em outro estudo, com 16 portadores de doenças crônicas, que estavam em processo de tratamento homeopático e que visou, entre outros objetivos, identificar as terapias utilizadas de modo concomitante ao tratamento homeopático, encontrou-se que a alopatia era a mais usada, mas também foram citadas a acupuntura, fitoterapia, psicologia e terapia ocupacional. O estudo encontrou, também, que a indicação/recomendação do médico homeopata e a busca pelo próprio bem-estar foram os motivos citados para a utilização destas outras terapias ${ }^{(16)}$. Isto nos mostra que há uma mobilização dos profissionais médicos na indicação destas terapias alternativas, como a fitoterapia. A busca pelo bem-estar, outro motivo relatado pelos pacientes, também é muito interessante, ressaltando que os mesmos querem outras formas de tratamento quando não estão satisfeitos ou se sentindo bem.

Um total de 153 docentes de cursos de graduação em Enfermagem e Medicina, de três diferentes faculdades, também realizou um estudo em que ficou claro que a maioria dos docentes de Enfermagem considera que o uso de plantas vem de um saber misto, tanto científico quanto popular. Já os docentes de Medicina o consideram um saber popular. Seu uso como recurso terapêutico foi mais citado pelos docentes da Enfermagem. As diferentes abordagens entre enfermeiros e médicos foram explicadas pela maior proximidade dos enfermeiros com a população. Sendo assim, é necessário que os profissionais de saúde tenham, durante a formação, o conhecimento sobre plantas medicinais, sendo que os conteúdos relacionados devem ser incluídos nos currículos das universidades ${ }^{(17)}$.

Além das tentativas incluir o conhecimento sobre as práticas populares de saúde nos currículos das Universidades, esforços estão sendo feitos no sentido de incorporá-lo no atendimento à população. Este fato pode ser comprovado pela aprovação, em 2006, da Política Nacional de Práticas Integrativas e Complementares no Sistema Único de Saúde, que propõe incorporar e implementar a medicina tradicional chinesa, acupuntura, homeopatia, plantas medicinais e fitoterapia, e termalismo social/crenoterapia no SUS ${ }^{(18)}$. Tais fatos nos mostram que não podemos ignorar estes tratamentos no serviço de saúde tradicional, pois, como vimos, eles são muito conhecidos e utilizados pela população.

É importante salientar que muitas das mães disseram que usariam ou vão usar os tratamentos alternativos em seus $\mathrm{RN}$, em casa. Caso tivessem recebido 
a alta hospitalar antes da descoberta da doença, elas tratariam seus filhos com aqueles recursos. Isto nos leva a refletir que novos estudos devem ser realizados no sentido de procurar descobrir a verdadeira função terapêutica dos tratamentos citados, para que possam ser supervisionados pelos profissionais, principalmente aqueles da atenção básica, que estão em contato direto com a população.

Além de conhecer os tratamentos e supervisioná-los, é preciso estar sempre atentos ao encaminhamento e orientação das mães para procurar os serviços de saúde caso não percebam melhora na coloração do RN após o uso destes tratamentos.

Temos que ressaltar, também, que as mães entrevistadas estavam internadas com seu $\mathrm{RN}$ em uma maternidade e que o mesmo estava recebendo o tratamento fototerápico, sendo as mães impossibilitadas de utilizar outro tipo de tratamento na ocasião. Mesmo assim, muitas o citaram, o que mostra algum conhecimento a respeito.

\section{CONSIDERAÇÕES FINAIS}

Quando as mães foram questionadas se conheciam algum tratamento alternativo para cuidar da icterícia, 77\% delas deram resposta positiva. Os tratamentos citados foram os banhos de picão, de telha virgem, de rosa-branca e de sol. Algumas mães tinham somente ouvido falar dos tratamentos, outras já usaram e funcionou, outras já usaram e não funcionou e algumas ainda pretendem usar.

A cultura popular está muito presente na sociedade, e vemos que os tratamentos caseiros ainda são muito difundidos. Muitas pessoas acreditam nestes tratamentos e fazem uso dos mesmos. Os profissionais de saúde devem estar bem orientados sobre os tratamentos, para orientar as mães neste aspecto. Sabemos que o banho de sol, por exemplo, é prescrito por muitos profissionais, e que possui resultados quando a icterícia não atingiu níveis avançados. Não se deve subestimar o conhecimento das pessoas, pois muitas vezes o que funciona é o que elas acreditam. Para lidar com estas situações, os profissionais devem estar familiarizados com todas as pessoas da casa e devem ter uma relação horizontal com as mesmas, para que questões como esta sejam discutidas abertamente.

\section{REFERÊNCIAS}

1. Martinelli ALC. Icterícia. Medicina [Internet].
2004;37(3/4) [acesso em 01 jul 2007]. Disponível: http://tiny.cc/4cm9f

2. Vieira AA, Lima CLMA, Carvalho M, Moreira MEL. $\mathrm{O}$ uso da fototerapia em recém-nascidos: avaliação da prática clínica. Rev Bras Saúde Mater Infant. 2004;4(4):359-66.

3. Mello LC. Hiperbilirrubinemia indireta. In: Margotto PR. Assistência ao recém nascido de risco. $2^{\mathrm{a}}$ ed. Brasília: Hospital Anchieta Brasília; 2006. p.490-5.

4. Bernaldo AJ, Segre CAM. Bilirubin dosage in cord blood: could it predict neonatal hyperbilirubinemia? São Paulo Med J. [Internet]. 2004;122(3) [acesso em 13 jul 2007]. Disponível: http://tiny.cc/8lwz7

5. Costa HPF. Sociedade Brasileira de Pediatria. Departamento de Neonatologia. Tempo de permanência hospitalar do recém-nascido [Internet]. 2007 [acesso em 28 jun 2007]. Disponível: http://tiny.cc/9bnxl

6. Queiroz MS. Representações sobre saúde e doença: agentes de cura e pacientes no contexto do SUDS. Campinas: UNICAMP; 1991.

7. Barbosa MA, Siqueira KM, Brasil, VV, Bezerra ALQ. Crenças populares e recursos alternativos como práticas de saúde. Rev Enferm UERJ. [Internet]. 2004;12(1) [acesso em 15 jan 2009]. Disponível: http:// tiny.cc/8fjuy

8. Souza MA, Melo MB, Silveira Junior RS, Barbosa MA, Siqueira KM, Martins CA et al. Práticas populares adotadas nos cuidados em saúde da criança. Rev Enferm UERJ. [Internet]. 2006;14(4) [acesso em 13 mai 2008]. Disponível: http://tiny.cc/7u2s9

9. Wahren CG, Cunto CL. Medicinas alternativas: un tema que no puede ser ignorado. Arch Argent Pediatr. [internet]. 2004;102(2) [acesso em 15 jan 2009]. Disponível: http://tiny.cc/f6zvv

10. Fontanella F, Speck FP, Piovezan AP, Kulkamp IC. Conhecimento, acesso e aceitação das práticas integrativas e complementares em saúde por uma comunidade usuária do Sistema Único de Saúde na cidade de Tubarão/SC. Arq Catarin Med. [Internet]. 2007;36(2) [acesso em 15 jan 2009]. Disponível: http:// www.acm.org.br/revista

11. Moreira CT, Oliveira ATSA, Machado CA, Vasconcelos Neto JÁ, Machado MFAS. Crendices e práticas populares: influência na assistência de enfermagem prestada à criança no Programa Saúde da Família. Rev 
Bras Promoc Saúde. [Internet]. 2006;19(1) [acesso em 16 jan 2009]. Disponível: http://tiny.cc/lu556

12. Bardin L. Análise de conteúdo. Lisboa: Edições 70; 1977.

13. Plantas que curam. O maior cadastro de plantas medicinais da internet brasileira. Picão [Internet]. 2000 [acesso em 15 abr 2008]. Disponível: http://tiny. cc/lcblf

14. Camargo Júnior WP. Secretaria Municipal de Campinas. Primeiras Orientações e Cuidados com o Recém-Nascido (RN). [Internet] 2000 [acesso em 21 mar 2008]. Disponível: http://tiny.cc/5joi1

15. Alves AR, Silva MJP. O uso da fitoterapia no cuidado de crianças com até cinco anos em área central e periférica da cidade de São Paulo. Rev Esc Enferm USP. 2003;37(4):85-91.

16. Santos JR, Zanelatto PF, Barbosa MA, Medeiros M. A utilização da homeopatia associada a outras terapias para o Tratamento de doenças crônicas. Cogitare Enferm. [Internet] 2009;14(1) [acesso 20 ago 2009]. Disponível: http://tiny.cc/byku6

17. Sena J, Soares MCF, Cezar-vaz MR, Sena A, MuccilloBaisch AL. Visão docente sobre plantas medicinais como um saber e sua utilização como medicamento. Rev Enferm UERJ. [Internet] 2006;14(2) [acesso em 15 jan 2009]. Disponível: http://tiny.cc/mxi9o

18. Ministério da Saúde (BR). Secretaria de Atenção à Saúde. Departamento de Atenção Básica. Política Nacional de Práticas Integrativas e Complementares no SUS - PNPIC-SUS [Internet]. Brasília: Ministério da Saúde, 2006 [acesso em 15 jan 2009]. Disponível: http://tiny.cc/jwn6u 